\title{
Planning a rota: some thoughts to ponder
}

In the interests of simplicity we invariably refer to all persons in the text as "he". This is not meant to be in any way disparaging. The author has an excuse for such confusion. In Gaelic even the bull is feminine!

\section{Before you begin}

The design of the various rotas in an accident and emergency department is a time consuming and largely thankless task, but in these days of shortages of medical staff at all levels, an equitable rota is an important way of making YOUR post appear more attractive than some others. Thought and planning are therefore important. Beware-this planning cannot be done quickly. As soon as you think you have solved one problem, you will realise that you have just created another. Analgesia for the inevitable headache is useful prophylaxis, but alcohol should be avoided as a lateral thinking brain is essential. Computer programs are available for rota planning. I recently asked a friend who is a personnel manager in industry to use his very expensive program to design a rota for 11 SHOs. Two weeks and a burnt out microchip later the answer came back... "Too many variables!!!"

When the rota is published you will inevitably be blamed for any inconsistencies ("he's got one less night shift in 3 months than I have"). It is impossible to please everyone. If the rota includes yourself, expect it to be carefully scrutinised to ensure that you are doing your share, but resist the temptation to assume the burden yourself when things get tight, otherwise you will end up doing too much in the interests of "fairness" for others.

Unfortunately, patients like to attend when they are not working, so busy periods tend to be at times which are unsociable for the rest of us. When rostering SHOs and other shop floor workers (including middle grades and seniors) ensuring adequate out of hours cover means unpopular shifts. There is no easy solution unless (dream on) money is freely available for sessional assistance. Publishing the rota as far in advance as possible gives people a chance to make alternative arrangements or organise swaps for particular days. Ensure that those swapping let you know of the arrangement, and that a master copy of the rota is kept updated. The worker who forgets the arrangement at the last minute can then be effectively reminded. As your rota manager may not be instantly available to answer queries at shift changeover, it is wise to build a rota that makes it difficult for doctors to swap their shifts. This causes minor difficulties for the manager but in the long term reduces stress levels.

We are of course constrained in what we do with our resources by rules. They guide us on how long shifts can be, how many hours we work in a week, and the length of rest periods. These rules are likely to get tighter, as is the need to increase time for protected training. We live in a "can do" world, and health service managers are well aware of this fact.

\section{Questions to ask yourself}

There are inevitable differences between rotas for different grades of staff, but some problems are common to all.

1. What pattern of shift is to be worked? How are you going to arrange meals, sleeping accommodation, and cover any additional costs within a given system?
2. On which days is your department busiest and at which time of day? If seasonal variations in workload are high you will need additional staff for the peak period.

3. What is your "acceptable" waiting time? Staff the department on that basis. How many staff of which grade are needed at any one time?

Your managers, and if possible your patients, need to know that staffing for "average" business will not cover the peaks and troughs of the workload in our demand driven service. If you find a foolproof way of doing this please let us all know.

There is no single solution which works for all departments. You must work out the most appropriate method for your circumstances even if this means considerable original thought.

\section{The problems with SHOs}

Full shifts are costly, but are popular, even if sometimes antisocial. When they're off they are truly off, can get drunk (never) without fear of being hauled back, and generally they get plenty of time to recuperate. Partial shifts are less popular. They tend to produce a longer working week, and you end up paying people to sleep. Your choice depends on the balance between workload and available doctor hours.

"Progressive" rotas where each shift starts later and extends into the evening are useful. For example one doctor may work 8-6, the next 9-7, the next 11-9, and the next $1-10$. This provides good evening cover and is not too antisocial if the SHOs work a later or earlier shift each successive day.

The more juniors you have, the more complicated the rota, and the more cover is needed for leave, study leave, and "emergencies". Don't think that more staff means more flexibility. The constraints on junior doctors' hours have largely removed the ability to cover internally. Holidays can be particularly difficult. Fixing holidays in advance is probably the easiest way to plan. It works better than you might expect if the SHOs are warned that this is the system. Tell them in the job description and remind them at interview. This gives them time to submit requests for leave in advance and allows them to be slotted into the appropriate line on the rota. It is just possible to force the postponement of a honeymoon to fit in with your rota, but such inflexibility will not make you popular, nor, I suggest, fill your posts in the future.

Study leave - to be encouraged - can cause major problems with the rota, particularly if more than half your SHOs want to attend the same course. Remember that protected teaching time in the department counts towards study leave allowances.

Eventually you will create a rota with which everyone is reasonably happy. This works well until one of the participants is ill! There are few departments which have the luxury of adequate flexibility. Getting a locum, especially at short notice, is always a nightmare. Locum agencies can sometimes help, particularly in the major centres, but at 
considerable cost and with variable quality. Even if the locum is experienced, there is a fair chance that he will not have worked in your department, or hospital, before. It is better for quality of care if a list of former SHOs, local general practitioners, and interested others is maintained. This means more work for the business manager or staffing department in contacting them, but the result is much more acceptable. It is also worthwhile being generous. Allow the odd day to be added to a period of leave to make travelling easier. This can always be used as a lever when disaster strikes, and greatly reduces the amount of arm twisting necessary to fill a gap.

\section{The middle grades}

Here you may wish to relax. After a brief discussion with them, to agree the duration and level of cover required, the middle grade staff can gain valuable experience producing their own rota. Basic ground rules will define the number of middle grades who can be "away" at the same time, the arrangements for "research and study", the level of "front line work" and any other contentious points.

In departments with one or two consultants and small numbers of middle grades, it may be sensible to include everyone in a "senior doctors" rota, spreading the load more equitably. It is then important that middle grades do not always work with the same consultant. Variations on a theme are always useful. From the consultant's viewpoint, a final year specialist registrar should need less supervision than a first year.

\section{Solving consultant dilemmas?}

Most consultants agree that time spent supervising SHOs and discussing problems with middle grades is very valuable. Perhaps this part of the consultant's work should be allocated first. However, until personally experienced, it is difficult for trainees to imagine the sheer volume of paper which crosses the average consultant desk, and it is very easy for the busy clinical consultant to find himself still in the office at some ungodly hour at the expense of family, health, and sanity.

Fixing sessions is all too easy (and something that managers are keen on) but may be very difficult to fulfil when colleagues are absent. Our specialty is attractive to many of us because of the variety it provides, and by its very nature the demands on our time must vary if patients are to be well served. In my job plan (which contains only five fixed sessions) is the phrase:
"In recognition of the special circumstances which apply to Accident $\mathcal{E}$ Emergency work it is agreed that these fixed sessions may from time to time need to be worked flexibly throughout the week in order to ensure that they are achieved."

Some such phrase is recommended, especially if a lot of fixed sessions are expected.

Some things are, however, better fixed. Follow up clinics, minor operation lists, and special interest sessions are probably best done by the same person at the same time each week. In the interests of communication it is essential that all the seniors meet regularly once a week for an hour or two to discuss problems and policies so, for at least a brief period, no matter how complicated and flexible the rota, everyone should be in the same place at the same time.

When there is only one consultant, no one expects him to be there all the time. As numbers increase there is a disproportional expectation of consultant availability. You and your colleagues must agree how much time each of you will spend "at the front desk" and how (if at all) you will cover each other's sessions.

Inevitably, more managerial roles seem to creep up on all of us, indeed some even seek these tasks. The effect of these roles on your own time and on that of colleagues must be borne in mind. What are you going to give up to undertake this new role effectively? Beware of spreading yourself too thinly and not actually achieving any of the goals.

\section{And finally}

Planning a rota can be tedious and time consuming, but is nonetheless a positive challenge. Why not try something totally different? How about doctors and nurses working the same shifts?

In one $A \& E$ department, on an experimental basis, all the staff worked in teams led by a senior doctor. Doctors, nurses, radiographers, physio, plaster technician, receptionists, and even the secretary all worked the same rota. For three months the same people worked together on every shift. Team building at its best? It seemed to workbut for how long?

This brief article has probably raised more questions than it has answered but hopefully it has stimulated some thought. Rota solutions which work should be shared.

IAIN C GRANT

Accident and Emergency Department, Derriford Hospital, Plymouth

\section{How to find an SHO}

Although some hospitals may still be in the happy position of having at least one and possibly more applicants for every SHO post, the shortage of SHOs (particularly in $\mathrm{A} \& \mathrm{E}$ ) is now well known and before one can appoint, one must attract suitable applicants. I give a few ideas below. These should not be considered as a way of solving a crisis, as in the long run the methods one uses to attract good staff and the methods one employs to run a good department are identical.

It is important that the job offers good experience. This is not just experience of practical procedures; with the range of conditions seen in the department one of the most important skills to be learnt in A\&E is decision making. A department where SHOs are allowed to make decisions will be more attractive than one in which the decision to admit or discharge is always made after referral for a specialist opinion. Good support for SHOs in this decision making is essential. Consultants may argue about being resident on call, but for patients and SHOs there can be little doubt that 24 hour senior or middle grade cover in the department is the ideal. This is not always possible but one should aim for someone more senior than an SHO to be in the department for as many of the 168 hours a week as is possible, and SHOs should know where they can get help in the absence of more senior A\&E staff (for example, trauma team). Support should be more than nominal: a presence in the consulting room is much more valuable than advice over a phone. Sensible rotas are a must: all SHOs will appreciate that the department must be staffed continuously, but do not use them just to fill the difficult times that staff grade doctors won't work! Consider links with other departments to form rotations. 